\title{
The Influence of Backrest Inclination on Buttock Pressure
}

\author{
Un Jin Park, M.D., Seong Ho Jang, M.D.
}

Department of Rehabilitation Medicine, Hanyang University College of Medicine, Guri 471-701, Korea

Objective To assess the effects of backrest inclination of a wheelchair on buttock pressures in spinal cord injured (SCI) patients and normal subjects.

Method The participants were 22 healthy subjects and 22 SCI patients. Buttock pressures of the participants were measured by a Tekscan ${ }^{\circledR}$ pressure sensing mat and software while they were sitting in a reclining wheelchair. Buttock pressures were recorded for $90^{\circ}, 100^{\circ}, 110^{\circ}, 120^{\circ}$ and $130^{\circ}$ seat-to-back angles at the ischial tuberosity (IT) and sacrococcygeal (SC) areas. Recordings were made at each angle over four seconds at a sampling rate of $10 \mathrm{~Hz}$. Results The side-to-side buttock pressure differences in the IT area for the SCI patients was significantly greater than for the normal subjects. There was no significant difference between the SCI patients and the normal subjects in the buttock pressure change pattern of the IT area. Significant increases in pressure on the SC area were found as backrest inclination angle was changed to $90^{\circ}, 100^{\circ}$ and $110^{\circ}$ in the normal subjects, but no significant differences were found in the SCI patients.

Conclusion Most of the SCI patients have freeform posture in wheelchairs, and this leads to an uneven distribution of buttock pressure. In the SCI patients, the peak pressure in the IT area reduced as the backrest angle was increased, but peak pressure at the SC area remained relatively unchanged. To reduce buttock pressure and prevent pressure ulcers and enhance ulcer healing, it can be helpful for tetraplegic patients, to have wheelchair seat-to-back angles above $120^{\circ}$.

Key Words Wheelchair, Pressure ulcer, Backrest, Inclination

Received June 28, 2011; Accepted September 20, 2011

Corresponding author: Seong Ho Jang

Department of Rehabilitation Medicine, Guri Hospital, Hanyang University College of Medicine, 249-1, Gyomun-dong, Guri 471-701, Korea

Tel: +82-31-560-2380, Fax: +82-31-564-4654, E-mail: systole@naver.com

(a) This is an open-access article distributed under the terms of the Creative Commons Attribution Non-Commercial License (http:// creativecommons.org/licenses/by-nc/3.0) which permits unrestricted noncommercial use, distribution, and reproduction in any medium, provided the original work is properly cited.

Copyright $\odot 2011$ by Korean Academy of Rehabilitation Medicine

\section{INTRODUCTION}

Pressure ulcers occur if pressure is concentrated over a bony protrusion when someone remains in the same position for many hours. They are one of the serious complications, which may occur in people with chronic diseases such as patients with a spinal cord injury or a brain disease, and they result in an increased numbers of days in hospital for treatment and delays in rehabilitation. They are also a major cause of death due to a deterioration in cardio-respiratory function and septicemia. $^{1,2}$ 
Pressure ulcers are known to occur in $25 \%$ to $85 \%$ of SCI patients and to occur easily and frequently in the ischial tuberosity (IT) and sacrococcygeal (SC) areas, especially in case of SCI patients who remain seated for much of the time. ${ }^{3-7}$ It is known that at least one pressure ulcer occurs in $30 \%$ of SCI patients within several years after injury, that pressure ulcers occur in $60 \%$ of patients with complete tetraplegia and $50 \%$ of patients with complete paraplegia, and that they lead to a rise in morbidity and mortality. ${ }^{7-9}$

Pressure ulcers are considered to be an important complication which extends the period of hospitalization for many patients, increases medical costs, and make positive rehabilitation difficult. Considerable time and costs are reported to be spent on curing pressure ulcers. In England two billion pounds every year are needed for the medical expenses associated with pressure ulcers, and in America the costs range from an average of 15,000 dollars to over 30,000 dollars for each pressure ulcer site. ${ }^{5,6,10,11}$ Accordingly, efforts to understand the cause and pathogenesis of pressure ulcers are very important.

A pressure ulcer is thought to be due to the interruption of blood flow by external pressure, which results in necrosis of tissue. ${ }^{12}$ The causes are a mixture of internal and external factors. Several factors such as external pressure and shear stress, temperature, humidity, hygiene, nutrition, a deterioration in sensory and motor function, and posture can contribute in various combinations with each other. ${ }^{13}$

A systematic analysis of the factors which could be used effectively to prevent pressure ulcers suggests pressure and posture because both can controlled by wheelchair design, correcting posture and the use of assistive devices like special cushions.

When someone adopts a sitting posture in a wheelchair without movement, the skin, subcutaneous tissue, fat, and muscles are pressed together, thereby leading to soft tissue changes between regions of bony protrusions like the IT and SC areas and the supporting surface. The physical load is concentrated in the contact area of bone and soft tissue. ${ }^{14}$ When the pressure, which is added to the buttock-interface side, becomes high enough to exceed the average capillary pressure, the capillaries collapse. If this situation continues for several hours, then segmental ischemia occurs, and this leads to the development of a pressure ulcer. ${ }^{15}$ Following a spinal cord injury, muscles are contracted and other soft tissues are lost. Consequently, the buttock-interface area is reduced, and the pressure dispersion effect of subcutaneous tissue is thereby decreased. ${ }^{16,17}$ Pressure is defined as the force applied per unit area, which means that pressure increases if the contact area is reduced. Gutierrez et al. ${ }^{18}$ and Aissaoui et al. ${ }^{19}$ reported that the buttock-interface area of SCI patients is about almost $50 \%$ smaller than in normal subjects, and buttock pressure is therefore about doubled in SCI patients of the same weight as normal subjects.

In 1985, Drummond et al. ${ }^{20}$ suggested the criteria for the occurrence of pressure ulcers. Pressure ulcer occurred when $30 \%$ or more of body weight was distributed over the IT area on either side, or when $11 \%$ or more was distributed over the SC area. These weight distributions appeared to occur frequently in spinal scoliosis or pelvic torticollis.

Also, in 2004, Gutierrez et al. ${ }^{18}$ had subjects sit on a wooden table and in wheelchair and showed that SCI patients displayed a more asymmetric buttock pressure and smaller contact area than normal subjects. An asymmetric sitting posture adds more pressure to IT area in one side, and therefore leads to the increasing possibility of a pressure ulcer occurring.

Accordingly, in order to reduce the occurrence of pressure ulcers, attempts should be made to help SCI patients in wheelchairs to control posture so that buttock pressure is reduced. Research studies have been done to assess the potential benefits of postural management and specially designed cushions to relieve buttock pressure. Other research studies have been also done to measure buttock pressure change by time flow in SCI patients and during wheelchair moving. ${ }^{9,21-23}$ However, no research has been reported on changing buttock pressure by varying the backrest angle of wheelchair or on the most appropriate backrest angle. Accordingly, this study aimed to investigate the effect of the backrest angle of a wheelchair on the unequal distribution of buttock pressure shown by SCI patients and to do this by measuring and comparing buttock pressures in SCI patients and normal subjects at different backrest angles. A further aim was to offer basic reference data on the ideal angle when using a reclining wheelchair.

The research hypotheses are (1) that the differences between left and right side buttock pressures will be 
greater in SCI patients than in normal subjects due to reduced postural control in SCI patients and their tendency to incline either to the left or right side when sitting in a wheelchair, and (2) that the pattern of buttock pressures according to changes in backrest angles in SCI patients will be different from that in normal subjects.

\section{MATERIALS AND METHODS}

\section{Subjects}

The participants were 22 healthy adult men and 22 male patients with spinal cord injury. The SCI patients were inpatients of the ward for spinal cord injury at the National Rehabilitation Center and all used wheelchairs.

\section{Methods}

Subjects were seated in a neutral position in a wheelchair with a variable backrest angle. The same wheelchair was used for all subjects. A $44 \times 46 \mathrm{~cm}$ pressure mat with 1,558 sensors (Tekscan Inc., South Boston, USA) was positioned on a hard sheet, which had been placed on the bottom of the wheelchair. Backward backrest angles were varied at $10^{\circ}$ intervals between $90^{\circ}$ and $130^{\circ}$, and buttock pressures measured five times at each angle. For each measurement, buttock pressure data were collected for four seconds at a sampling rate of $10 \mathrm{~Hz}$ and were analyzed using Tekscan software after being stored in computer. The buttock was divided into IT and SC

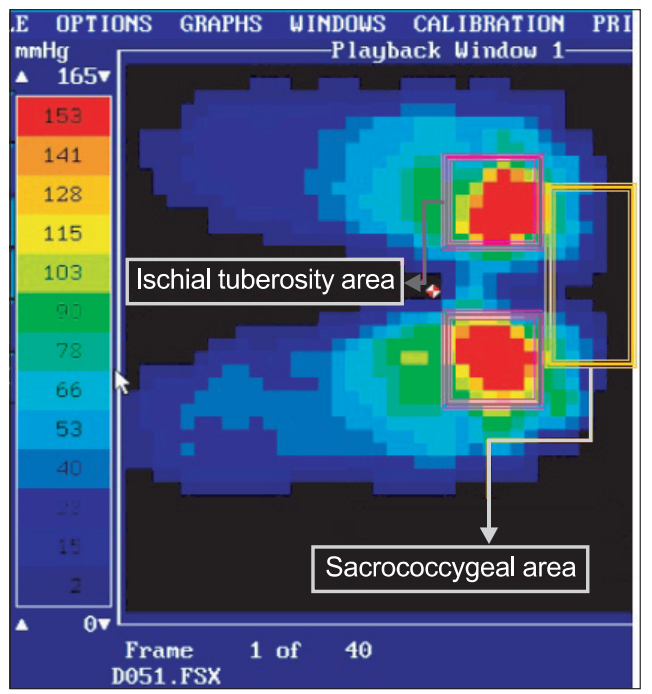

Fig. 1. Buttock pressure distribution in IT-SC areas as displayed on monitor. areas, and the peak pressure values at the peak pressure points in each area were measured and analyzed (Fig. 1). The IT areas were defined as the $7 \times 7 \mathrm{~cm}$ regions centered on the left and right side peak pressure points, which were measured at each backrest angle. The SC area was defined as the $7 \times 14 \mathrm{~cm}$ region, which was bordered by the two IT areas. The average pressure in each region was measured.

To evaluate postural differences, the peak pressures in the left side IT area were compared with those in the right side. The changing pattern in buttock pressure depending on backrest angle was examined in terms of the peak pressure and the average pressure in the IT and $\mathrm{SC}$ areas. For the IT area, the larger of the peak pressures for the left and right sides was used as the peak pressure for the whole area on the basis that this value had greater clinical significance. Finally, the pressure difference between the IT and SC areas (IT-SC) was the value of the SC area peak pressure deducted from the higher of the two (left and right) IT peak pressures.

\section{Statistical analysis}

The Mann-Whitney U-test was used to compare differences in age, weight, and BMI between normal subjects and individuals with spinal cord injury. The general linear model was used to compare changes in postural differences, IT pressure, SC pressure, and ITSC pressure for each group according to the different backrest angles. A repeated measures analysis of variance (ANOVA) was used for the comparisons between normal subjects and the SCI patients. Dunnett and Tukey tests were used to adjust confidence levels in the post hoc testing of the multiple comparisons at each back rest angle. All statistical analyses were performed using SPSS 18.0 for Windows, and statistical significance was set at $\mathrm{p} \leq 0.05$.

\section{RESULTS}

\section{General characteristics of subjects}

All participants were male. The average age, height, weight and BMI for the normal subject group were 27.2 years, $171.9 \mathrm{~cm}, 67.3 \mathrm{~kg}$ and $22.7 \mathrm{~kg} / \mathrm{m}^{2}$, respectively. The respective averages for the SCI patient group were 32.5 years, $168.8 \mathrm{~cm}, 60.9 \mathrm{~kg}$ and $21.4 \mathrm{~kg} / \mathrm{m}^{2}$. None of the differences between the two groups on these variables 
was statistically significant. Amongst the SCI patients, there were 9 (40.9\%) with complete injury, 13 (59.1\%) with incomplete injury, 10 (45.5\%) with tetraplegia and $12(54.5 \%)$ with paraplegia.

\section{Comparison of postural deviation}

For both the normal and SCI patient groups the size of the left-and-right IT pressure differences did not differ when the backrest angle was changed from $90^{\circ}$ to $130^{\circ}$. However, when the normal and SCI patients were compared in terms of the magnitude of the individual differences between the left and right IT pressures, the two groups differed significantly at every backrest angle, with the SCI group showing the larger differences in left-and-right IT pressures (Table 1). This suggests that the postural deviation of SCI patients was significantly greater than that of normal subjects at all angles.

An intra-individual multiple analysis revealed no significant changes in left-and-right pressure differences according to backrest angle in either the normal subjects or the SCI patients.

\section{A change in peak pressure of IT area}

In normal subjects, when the backrest angle of wheelchair was $90^{\circ}$, the average peak pressure of the IT area was $266.7 \pm 188.6 \mathrm{mmHg}$. When the backrest angle was increased in $10^{\circ}$ increments up to $130^{\circ}$, the average peak pressures were found to be $251.3 \pm 195.3 \mathrm{mmHg}$, $233.0 \pm 202.7 \mathrm{mmHg}, 183.8 \pm 166.5 \mathrm{mmHg}$ and $133.8 \pm 149.8$ $\mathrm{mmHg}$, respectively. When the wheelchair backrest angle was $90^{\circ}$ in SCI patients the average peak pressure of the IT area was $344.3 \pm 188.6 \mathrm{mmHg}$ and was $306.4 \pm 195.3 \mathrm{mmHg}$,

Table 1. Buttock Peak Pressure (mmHg) Differences between Right and Left IT Areas according to Seat-toBack Angle in Normal Subjects and Spinal Cord Injured Patients

\begin{tabular}{rll}
\hline & Normal & Patients \\
\hline $90^{\circ}$ & $11.6 \pm 23.5$ & $103.2 \pm 202.4^{*}$ \\
$100^{\circ}$ & $25.6 \pm 30.8$ & $142.8 \pm 187.3^{*}$ \\
$110^{\circ}$ & $43.8 \pm 42.3$ & $109.1 \pm 179.3$ \\
$120^{\circ}$ & $40.8 \pm 37.3$ & $110.8 \pm 141.5^{*}$ \\
$130^{\circ}$ & $25.6 \pm 24.8$ & $117.2 \pm 132.1^{*}$ \\
\hline
\end{tabular}

Values are mean \pm standard deviation ${ }^{*} \mathrm{p}<0.05$
$299.2 \pm 202.7 \mathrm{mmHg}, 236.7 \pm 166.5 \mathrm{mmHg}$, and $218.2 \pm 149.8$ $\mathrm{mmHg}$, respectively, as the angle was increased in $10^{\circ}$ steps up to $130^{\circ}$.

In both the normal subject and SCI patient group, the peak IT pressure changed significantly as the backrest angle altered from $90^{\circ}$ to $130^{\circ}$. An intra-individual multiple analysis of the results for the normal subjects showed no significant change in IT pressures from the $90^{\circ}$ to $110^{\circ}$ seat-to-back angles. However the IT pressure reduced after $120^{\circ}$ seat-to-back angle significantly, and there was significant reduction in IT pressures between the $120^{\circ}$ and $130^{\circ}$ seat-to-back angles. In case of the SCI patients, there was similarly no significant change in IT pressures from the $90^{\circ}$ to $110^{\circ}$ seat-to-back angles seatto-back angle However, while the peak pressures reduced after $120^{\circ}$, the difference in pressures between the $120^{\circ}$ and $130^{\circ}$ seat-to-back angles were not statistically significant.

The interaction between IT pressures according to backrest angle in the normal and SCI groups was 0.101 in the significant probability, which was modified in the intra-individual effect verification without supposing sphericity. Thus, the changing pattern in IT pressure between two groups didn't show significant difference.

However, the intra-individual effect analysis showed a significant difference, indicating that the IT pressure in SCI patients is higher than in normal subjects (Fig. 2).

\section{Changes in peak pressures of the $\mathrm{SC}$ area}

In normal subjects, when the backrest angle of the

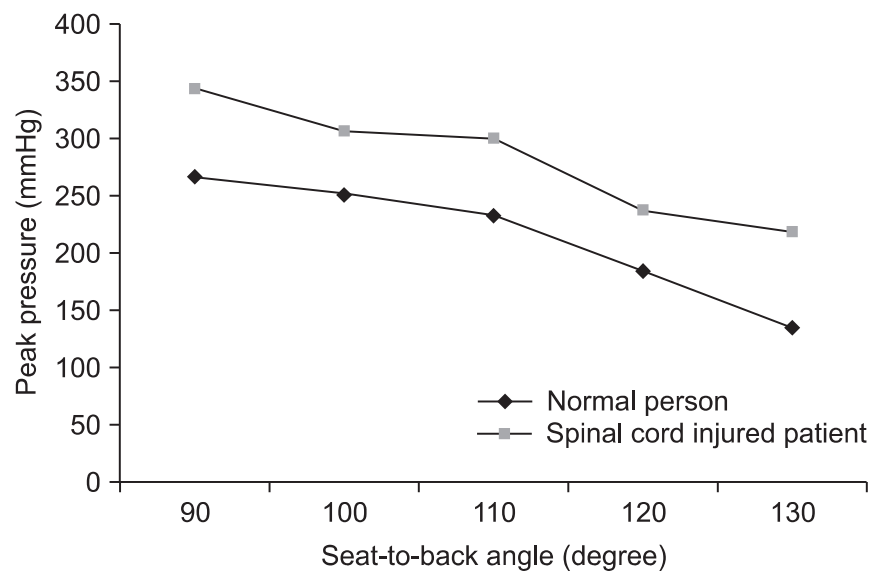

Fig. 2. Changes in the buttock peak pressure of the IT area according to seat-to-back angle in normal subjects and spinal cord injured patients. 
wheelchair was $90^{\circ}$, the average peak pressure of the SC area was $109.8 \pm 152.0 \mathrm{mmHg}$. The average peak pressure was found to be $207.2 \pm 173.0 \mathrm{mmHg}, 246.8 \pm 179.6$ $\mathrm{mmHg}, 268.0 \pm 194.3 \mathrm{mmHg}$, and $267.9 \pm 177.2 \mathrm{mmHg}$, respectively, as backrest angle was increased in steps of $10^{\circ}$. When backrest angle of wheelchair was $90^{\circ}$ for the SCI patients, the average peak pressure of the SC area was $335.6 \pm 152.0 \mathrm{mmHg}$ and was $381.6 \pm 173.0 \mathrm{mmHg}$, $382.2 \pm 179.6 \mathrm{mmHg}, 388.1 \pm 194.3 \mathrm{mmHg}$, and $390.6 \pm 177.2$ $\mathrm{mmHg}$, respectively, as the backrest angle was increased. As was the case for pressures in the IT area, the pressure from $90^{\circ}$ to $130^{\circ}$ changed significantly in both groups. In case of normal subjects, the peak pressure of the SC area increased significantly between the $90^{\circ}$ and $110^{\circ}$ seatto-back angles to seat-to-back angle, but there were no

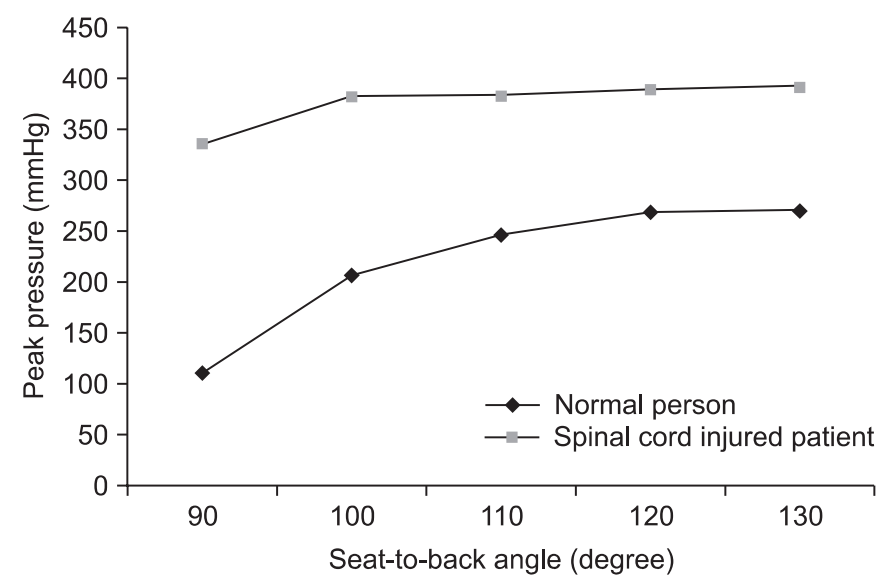

Fig. 3. Changes in the buttock peak pressure of the SC area according to seat-to-back angle in normal subjects and spinal cord injured patients.

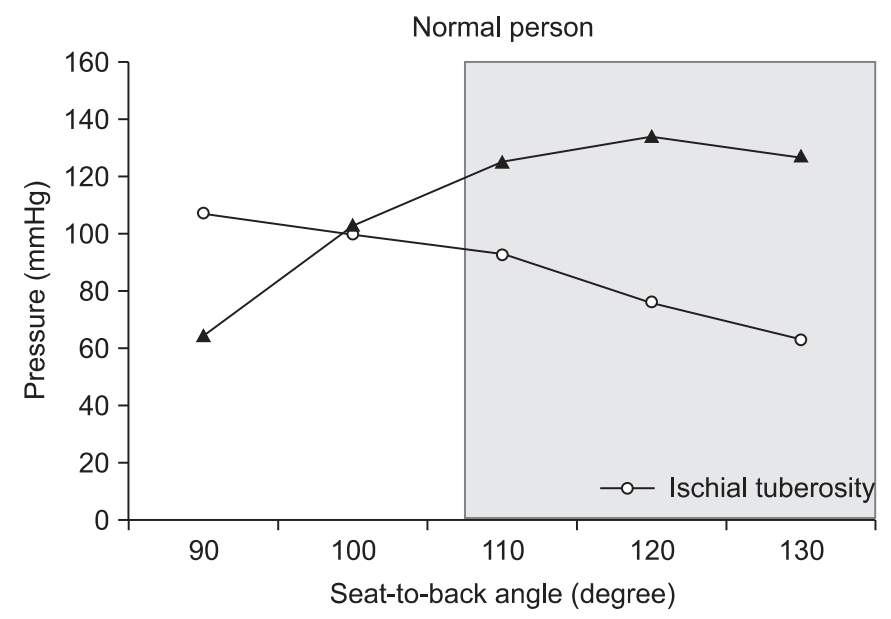

other significant differences in pressure between the remaining seat-to-back angles. The interaction between pressures of SC area according to backrest angle in groups with normal subjects and SCI patients was 0.046 in the significant probability, which was modified in the intra-individual effect verification without supposing sphericity. Thus, the changing pattern in pressure of SC area between two groups showed significant difference.

The peak pressures of the SC area were also found to be significantly higher in SCI patients than in normal subjects (Fig. 3).

\section{Difference in IT-SC pressures}

There were no significant differences in IT-SC pressures according to different backrest angles in either the normal subject or the SCI patient groups. In the intraindividual effect analysis, there were no significant differences in the IT-SC pressures between the various backrest angles in either normal subjects or the SCI patents. However, in normal subjects, the peak pressure

Table 2. Buttock Peak Pressure (mmHg) Differences between IT and SC Areas according to Seat-to-Back Angle in Normal Subjects and Spinal Cord Injured Patients

\begin{tabular}{lcc}
\hline & Normal & Patients \\
\hline $90^{\circ}$ & $162.8 \pm 61.2$ & $91.3 \pm 184.7$ \\
$100^{\circ}$ & $56.9 \pm 87.3$ & $2.6 \pm 182.4$ \\
$110^{\circ}$ & $8.1 \pm 68.2$ & $-27 \pm 228$ \\
$120^{\circ}$ & $-65.1 \pm 63.8$ & $-124.5 \pm 211.7$ \\
$130^{\circ}$ & $-121.3 \pm 51.8$ & $-118.4 \pm 238.4$ \\
\hline
\end{tabular}

Values are mean \pm standard deviation

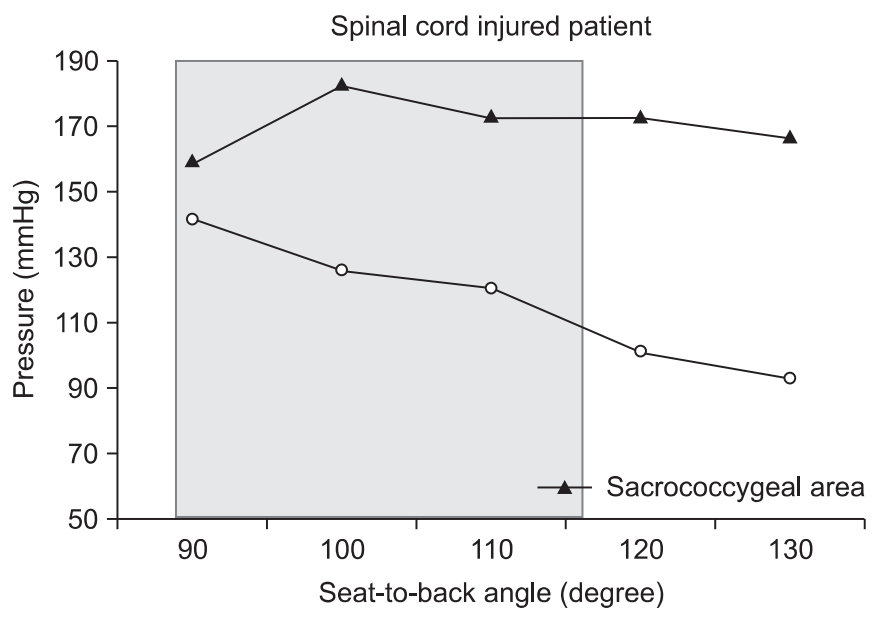

Fig. 4. Patterns of change in average pressure for normal subjects and spinal cord injured patients. The pressure change pattern of the disabled in gray box from $90^{\circ}$ seat-to-back angle is similar to that of normal subjects from $105^{\circ}$. 
of the SC area increased from $120^{\circ}$, and in SCI patients, the peak pressure of the SC area increased from $110^{\circ}$ (Table 2).

Comparison of the changing pattern between the average pressure and the peak pressure in the buttocks

To analyze the changing pattern in pressure, the average pressure was obtained in a $7 \times 7 \mathrm{~cm}$ region of the IT area and in a $7 \times 14 \mathrm{~cm}$ region of the SC area, centering on the peak pressure points. When the graphs of changes in the average pressure of the SC and IT areas for normal subjects and SCI patients are compared, the SC average pressure gradually increases as the backrest angle is inclined, while the IT average pressure gradually reduces. The cross-over point for the average pressure in the two regions for the normal subjects was at the seat-to-back angle of $99.3^{\circ}$. However, for the SCI patients, the crossover was as the seat-to-back angle of $86.1^{\circ}$, a difference of $13.2^{\circ}$. The change in buttock pressure of the SCI patients was similar to the pattern in normal subjects from $103.2^{\circ}$ (Fig. 4).

When the graphs of changes in the peak pressure of the SC and IT areas for normal subjects and SCI patients are compared, similarly the SC peak pressure gradually increases as the backrest angle is inclined, while the IT peak pressure gradually reduces. The cross-over in the peak pressure of the two regions for the normal subjects was at a seat-to-back angle of $107.6^{\circ}$. For the SCI patients, the cross-over occurs at angle of $91.6^{\circ}$, showing difference of $16^{\circ}$ between the two groups. The change in buttock pressure of SCI patients was similar to the pattern in

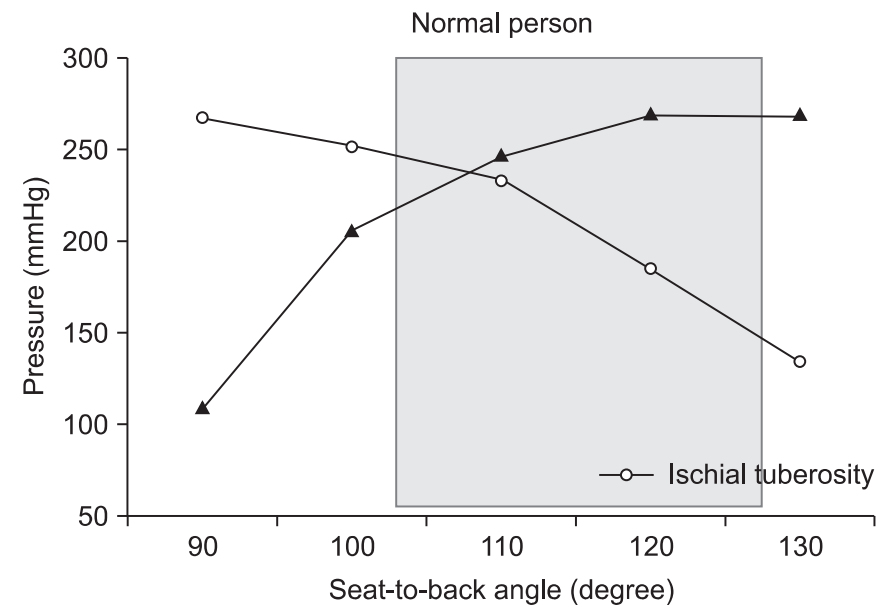

normal subjects from $106^{\circ}$ (Fig. 5).

\section{DISCUSSION}

In this study, postural difference, having more pressure on one side of the left-and-right sides of the IT area, was found to be significantly higher in SCI patients than in normal subjects. This postural imbalance in SCI patients could arise due to thoracic scoliosis caused by weakness of the paraspinal muscles. Thoracic scoliosis is known to become a serious risk as time passes following a spinal cord injury. ${ }^{24}$ Another possible explanation is the imbalance is a functional problem due to the use of general wheelchair by SCI, who tend to lean their bodies to the left or right because of decreased sense of balance. In 1992, Hobson and Tooms ${ }^{25}$ performed simple radiography at a $100^{\circ}$ seat-to-back angle in a wheelchair and found that the pelvic tilt of the coronal plane was $1.4^{\circ}$ for normal subjects and $3.2^{\circ}$ for SCI patients, indicating that the pelvis in SCI patients is inclined more to the left side or to the right side. However, the result was not statistically significant due to the small number of subjects. On the other hand, the left-and-right difference in buttock pressure found in the present study was statistically significant. There is therefore support for the conclusion that the pelvis in SCI patients is inclined to one side, either to the left or to the right. To prevent the deformity in the pelvis and spine and pressure ulcers on the buttocks, which may result, there is a primary need to use wheelchair suitable for the body size. There will be a need to use the ancillary equipment available for helping

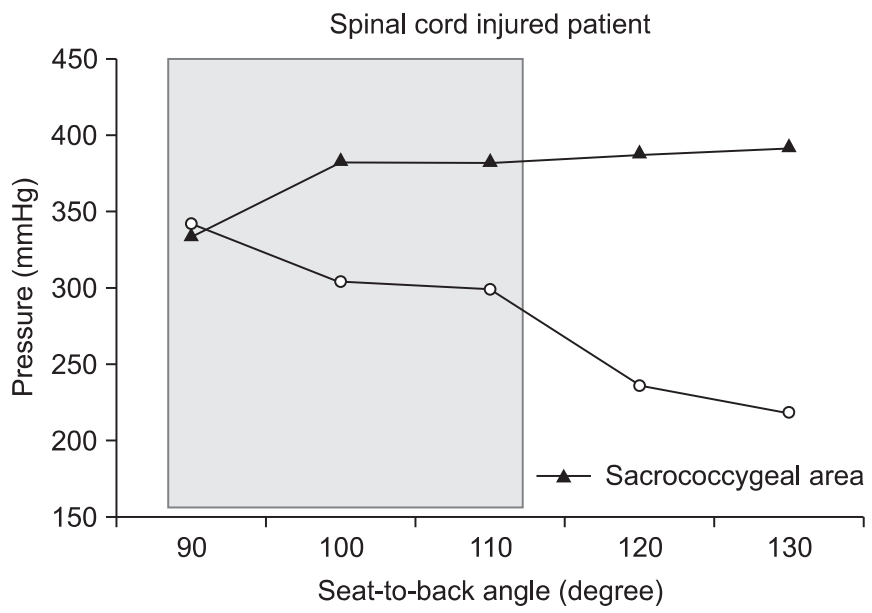

Fig. 5. Paterns of change in peak pressure for normal subjects and spinal cord injured patients. The pressure change pattern of the disabled group in gray box from $90^{\circ}$ seat-to-back angle is similar to that of the normal group from $105^{\circ}$ 
to stabilize the upper body and the customized cushion available for reducing buttock pressure, which is inclined to one side, and also a need for posture training. The postural differences in normal subjects and SCI patients did not change when the backrest angles of wheelchair were altered. This supports the finding of Andersson et al. ${ }^{26}$ that what lumbar lordosis increases with a rise in backrest angle up to $100^{\circ}$.

With regard to the differences in a change of pressure in the IT area between normal subjects and SCI patients according to backrest angle of wheelchair, the pressure in SCI patients was significantly higher. However, in the SC area, there was a difference between the two groups in the pattern of changes with different angles. In normal subjects, the pressure was observed to increase with each increase in angle. On the other hand, in case of SCI patients, the pressure was nearly unchanged as the angle increase. One explanation for this result could be the posterior tilting of the pelvis, which occurs in SCI patients. According to Hobson and Tooms, ${ }^{25}$ in wheelchair with a $100^{\circ}$ seat-to-back angle the pelvis in SCI patients tilted to the rear by about $15^{\circ}$ more than in normal subjects. In another study, it was shown that a considerable amount of lumbar lordosis is lost in changing from an upright posture to the sitting position, and inclining a backrest backwards does not have much effect on lumbar lordosis. The effect of increasing a backrest angle is mainly registered at the hip joint. ${ }^{26}$ Hence, a change in backrest angle is thought likely to be quite consistent with a change in pelvic tilt. When the wheelchair backrest is leant backward, this leads to posterior tilting in the pelvis. When this happens, the pressure on the IT area will reduce, and the pressure on the SC area will grow. If, as mentioned in above, the pelvis in SCI patients is already tilted more to the rear by $15^{\circ}$, the buttock pressure in SCI patients will be more focused into SC area, and it will simulate the same effect on them as if normal subjects are sitting on a wheelchair with the backrest tilted backward by $15^{\circ}$.

However, this hypothesis could not be directly addressed in the present study, which must rely on examining the correlation between pressures in the IT and SC areas.

First, in case of normal subjects, the pressure in the IT area was higher than in SC area at $90^{\circ}$ seat-to-back angle. With a rise in backrest angle, the pressure in the IT area reduces, whereas the pressure of SC area increases.
At a seat-to-back angle of $107.6^{\circ}$ which was displayed graphically, the pressures in IT area and SC area are the same; the difference in pressures of two areas becomes 0 . After this, the pressure in the SC area becomes higher than in the IT area. On the other hand, in case of SCI patients, the point at which the difference in the IT- SC pressures becomes 0 is seat-to-back angle of $91.6^{\circ}$. This suggests that the buttock pressure patterns at $91.6^{\circ}$ in SCI patients and at $107.6^{\circ}$ in normal subjects are equivalent, and this could imply that the posterior tilting of the pelvis in SCI patients is about $16^{\circ}$ more than in normal subjects. This difference is similar to that found by Hobson and Tooms. ${ }^{25} \mathrm{~A}$ fact, which backs up this implication, is that the pattern of changes for normal subjects is similar in the both the IT and SC areas and in IT- SC pressures for backrest angles of from $105^{\circ}$ to $130^{\circ}$ in normal subjects and in SCI patients for backrest angles of $90^{\circ}$ to $120^{\circ}$ in. However, all of this needs to be confirmed statistically by further research. Future studies should measure buttock pressures with $80^{\circ}$ to $180^{\circ}$ seat-to-back angles and incorporate radiographical measurements so that a more correct analysis is possible.

There are several possible explanations for the posterior tilting which occurs in SCI patients. Firstly, there is the weakness of the paraspinal muscles. Lancourt et al. ${ }^{24}$ asserted that kyphosis occurs following spinal cord injury due to weakness of the extension area in the spine, which is supported mainly by the spinal extensor, unlike the flexion area of the spine, which is supported mainly by a ligament; this leads to posterior tilting of the pelvis and consequently increases risk of pressure ulcers. According to Gardocki et al. ${ }^{27}$ in 2002 , posterior tilting in the pelvis occurs as a result of reduction in spinal lordosis. The lumbar kyphosis caused by the weakness of the paraspinal muscle can therefore be seen as the primary cause of posterior tilting in the pelvis of SCI patients. However, in contrast to the conclusions of Lancourt et al. ${ }^{24}$ the study by Hobson and Tooms ${ }^{25}$ SCI patients showed no lumbar kyphosis, but rather a slight lordosis when compared with normal subjects. Lancourt et al. ${ }^{24}$ measured canal curvature in the whole thoracolumbar region and had no control group, whereas Hobson and Tooms ${ }^{25}$ and Gardocki et al. ${ }^{27}$ targeted only the lumbar region. Additional research is therefore needed before accepting the conclusion that weakness of paraspinal muscle causes lumbar degenerative kyphosis, thereby 
leading to posterior tilting of the pelvis.

Secondly, there is a possibility of the buttocks gliding forwards due to muscular weakness. To prevent this, a patient should sit as close as possible to the rear of the wheelchair seat and use the foot support. Even so, it is possible that slipping forward will occur with different backrest angles. Thirdly, posterior tilting could arise due to shortening of the hamstring muscles. In SCI patients, contractures occur at a number of joints, and shortening of the hamstring muscles in a common occurrence. ${ }^{28}$ When the hamstring muscles shorten, the degree of pelvic flexion becomes limited, and the result of this will be a posterior slope in the pelvis. ${ }^{29}$

The buttocks are the areas where wheelchair users usually develop pressure ulcers. When the buttocks are divided into IT and SC areas, research suggests that more ulcers occur in the IT area (about 43\%) than in the SC area (about 33\%). However, some research has found that pressure ulcers are more common in the SC area. ${ }^{5,6,30-}$

${ }^{32}$ In the present study, there was no significant increase in peak pressure for the SC area as the backrest was tilted, and the pressure in the IT area reduced beyond an angle of $120^{\circ}$. In the study by Shields and $\operatorname{Cook}^{33}$ a significant change in the buttock pressure was reported to occur when the seat-to-back angle was changed by $10^{\circ}$. According to Henderson et al., ${ }^{34}$ a change of $35^{\circ}$ in seatto-back angle cannot be expected to cause a significant reduction in pressure. Only when there is a change of $65^{\circ}$ in seat-to-back angle will a substantial reduction in pressure occur. Nevertheless, increasing the seat-toback angle is recommended as a temporary means of preventing buttock pressure exceeding the threshold value for the occurrence of pressure ulcers. In these two studies the peak pressure interms of what was added to the whole buttock area. In the present study, pressure was measured in the two buttock areas where ulcers commonly develop so that the results are sensitive. In the end, tilting the wheelchair backrest backwards by over $30^{\circ}$ to prevent pressure ulcers will have no effect in the SC area, but it will prevent or reduce pressure ulcers in the IT area. However, patients with paraplegia need to propel their wheelchairs, and this is not easy to do with a $120^{\circ}$ seat-to-back angle. Furthermore, if a patient uses a $90^{\circ}$ or $100^{\circ}$ seat-to-back angle when propelling a wheelchair and $120^{\circ}$ angle when resting, there will be an increase in shear forces and the combination of these sources of sheer stress could increase the overall risk of pressure ulcers. $^{35}$

This study has several limitations. Firstly, the wheelchair used in the study was not modified to take into account individual differences. For example, the width, height, and armrest of the wheelchair used were not adapted to suit the body shape of each subject, and this may have reduced the validity of the pressure measurements. The positioning of the foot support illustrates this point. When the foot support is correctly positioned, pressure is dispersed over the femoral region, but when the foot support is positioned too high, the pressure is tilted to the rear, causing additional pressure to be distributed over the IT and SC areas. ${ }^{36}$ In case of the SCI patients in the present study, their average weight and height were less than in normal subjects. There was therefore little possibility that the foot support would be positioned too high. However, it was likely that the foot support was too low, causing the foot to dangle without support. This would have resulted in the possibility of the buttocks slipping further forward with the risk of additional pressure from contact with the front edge of the wheelchair seat. In future studies, patients with paraplegia and tetraplegia should be in separate groups, and as most SCI patients use a special cushion the effect of cushions should also be incorporated in the research design.

A second limitation is that there was no definite criteria of demarcating region to measure average pressures. In this study, an attempt was made to compare the average pressures measured within a certain region unlike other studies that measured the peak pressure in the IT or SC areas. However, the average pressure in the optionallydemarcated regions can't reflect the substantial average pressure in the IT and SC areas. For this reason, only the changing patterns of average pressure were compared.

\section{CONCLUSION}

When compared with normal subjects, SCI patients showed an asymmetric pressure distribution in a wheelchair between the left and right IT areas. The differences between normal subjects and SCI patients in the seat-to-back angles at which pressures in the IT and SC areas crossed as the seat-to-back angle was increased were approximately $13.2^{\circ}$ for average pressures and $16^{\circ}$ 
for peak pressures. This indicated that the pelvis in the SCI patients was tilted about $15^{\circ}$ backwards. Lumbar kyphosis due to weakness of the paraspinal muscles was considered as one of the explanations for posterior pelvic tilting.

As the wheelchair backrest angle was tilted backwards in SCI patients, the peak pressure in the IT area reduced, but the pressure in the SC area remained at about the same level. This suggests that pressure ulcers may be prevented or decreased in tetraplegia patients when the backrest angles of their wheelchairs are more than $120^{\circ}$.

\section{REFERENCES}

1. Kwon H, Jang IS, Lee JK, Lim P. Clinical observation of the pressure ulcer. J Korean Soc Plast Reconstr Surg 1996; 23: 818-826

2. Uhm KI, Lee YH, Jun KY, Lee YW. Clinical observations of pressure ulcer. J Korean Soc Plast Reconstr Surg 1980; 7: 281-289

3. Dowling AS. Pressure sores-their cause, prevention, and treatment. Md State Med J 1970; 19: 131-134

4. Fuhrer MJ, Garber SL, Rintala DH, Clearman R, Hart KA. Pressure ulcers in community-resident persons with spinal cord injury: prevalence and risk factors. Arch Phys Med Rehabil 1993; 74: 1172-1177

5. Kernozek TW, Lewin JE. Seat interface pressures of individuals with paraplegia: influence of dynamic wheelchair locomotion compared with static seated measurements. Arch Phys Med Rehabil 1998; 79: 313316

6. Richardson RR, Meyer PR Jr. Prevalence and incidence of pressure ulcers in acute spinal cord injuries. Paraplegia 1981; 19: 235-247

7. Rodriguez GP, Garber SL. Prospective study of pressure ulcer risk in spinal cord injury patients. Paraplegia 1994; 32: 150-158

8. Hackler RH. A 25-year prospective mortality study in the spinal cord injured patient: comparison with long-term living paraplegic. J Urol 1977; 117: 486-488

9. Staas WE Jr, Cioschi HM. Pressure sores-a multifaceted approach to prevention and treatment. West J Med 1991; 154: 539-544

10. Pressure sores-a ticking time-bomb. Intensive Crit Care Nurs 1995; 11: 44-48

11. Edberg EL, Cerny K, Stauffer ES. Prevention and treatment of pressure sores. Phys Ther 1973; 53: 246252

12. Kosiak M. Etiology of decubitus ulcers. Arch Phys Med Rehabil 1961; 42: 19-29

13. Byrne DW, Salzberg CA. Major risk factors for pressure ulcers in the spinal cord disabled: a literature review. Spinal Cord 1996; 34: 255-263

14. Linder-Ganz E, Gefen A. Mechanical compressioninduced pressure sores in rat hindlimb: muscle stiffness, histology, and computational models. J Appl Physiol 2004; 96: 2034-2049

15. Allen V, Ryan DW, Lomax N, Murray A. Accuracy of interface pressure measurement systems. J Biomed Eng 1993; 15: 344-348

16. Castro MJ, Apple DF Jr, Staron RS, Campos GE, Dudley GA. Influence of complete spinal cord injury on skeletal muscle within 6 mo of injury. J Appl Physiol 1999; 86: 350-358

17. Modelsky CM, Bickel CS, Slade JM, Meyer RA, Cureton KJ, Dudley GA. Assessment of skeletal muscle mass in men with spinal cord injury using dual-energy X-ray absorptiometry and magnetic resonance imaging. J Appl Physiol 2004; 96: 561-565

18. Gutierrez EM, Alm M, Hultling C, Saraste H. Measuring seating pressure, area, and asymmetry in persons with spinal cord injury. Eur Spine J 2004; 13: 374-379

19. Aissaoui R, Kauffmann C, Dansereau J, de Guise JA. Analysis of pressure distribution at the body-seat interface in able-bodied and paraplegic subjects using a deformable active contour algorithm. Med Eng Phys 2001; 23: 359-367

20. Drummond D, Breed AL, Narechania R. Relationship of spine deformity and pelvic obliquity on sitting pressure distributions and decubitus ulceration. J Pediatr Orthop 1985; 5: 396-402

21. Henderson JL, Price SH, Brandstater ME, Mandac BR. Efficacy of three measures to relieve pressure in seated persons with spinal cord injury. Arch Phys Med Rehabil 1994; 75: 535-539

22. Koo TK, Mak AF, Lee YL. Posture effect on seating interface biomechanics: comparison between two seating cushions. Arch Phys Med Rehabil 1996; 77: 4047

23. Rosenthal MJ, Felton RM, Hileman DL, Lee M, Friedman M, Navach JH. A wheelchair cushion 
designed to redistribute sites of sitting pressure. Arch Phys Med Rehabil 1996; 77: 278-282

24. Lancourt JE, Dickson JH, Carter RE. Paralytic spinal deformity following traumatic spinal-cord injury in children and adolesents. J Bone Joint Surg Am 1981; 63: 47-53

25. Hobson DA, Tooms RE. Seated lumbar/pelvic alignment. A comparison between spinal cord-injured and noninjured groups. Spine 1992; 17: 293-298

26. Andersson GB, Murphy RW, Ortengren R, Nachemson AL. The influence of backrest inclination and lumbar support on lumbar lordosis. Spine 1979; 4: 52-58

27. Gardocki RJ, Watkins RG, Williams LA. Measurements of lumbopelvic lordosis using the pelvic radius technique as it correlates with sagittal spinal balance and sacral translation. Spine Journal 2002; 2: 421-429

28. Yarkony GM, Bass LM, Keenan V 3rd, Meyer PR Jr. Contractures complicating spinal cord injury: incidence and comparison between spinal cord centre and general hospital acute care. Paraplegia 1985; 23: 265-271

29. Gajdosik RL, Albert CR, Mitman JJ. Influence of hamstring length on the standing position and flexion range of motion of the pelvic angle, lumbar angle, and thoracic angle. J Orthop Sports Phys Ther 1994; 20: 213-219
30. Sumiya T, Kawamura K, Tokuhiro A, Takechi H, Ogata H. A survey of wheelchair use by paraplegic individuals in Japan. Part 2: Prevalence of pressure sores. Spinal Cord 1997; 35: 595-598

31. Schue RM, Langemo DK. Pressure ulcer prevalence and incidence and a modification of the Braden Scale for a rehabilitation unit. J Wound Ostomy Continence Nurs 1998; 25: 36-43

32. Hanson DS, Langemo D, Olson B, Hunter S, Burd C. Evaluation of pressure ulcer prevalence rates for hospice patients post-implementation of pressure ulcer protocols. Am J Hosp Palliat Care 1994; 11: 14-19

33. Shields RK, Cook TM. Effect of seat angle and lumbar support on seated buttock pressure. Phys Ther 1988; 68: $1682-1686$

34. Henderson JL, Price SH, Brandstater ME, Mandac BR. Efficacy of three measures to relieve pressure in seated persons with spinal cord injury. Arch Phys Med Rehabil 1994; 75: 535-539

35. Tam EW, Mak AF, Lam WN, Evans JH, Chow YY. Pelvic movement and interface pressure distribution during manual wheelchair propulsion. Arch Phys Med Rehabil 2003; 84: 1466-1472

36. Bush CA. Study of pressures on skin under ischial tuberosities and thighs during sitting. Arch Phys Rehabil 1969; 50: 207-213 